\title{
Educação e Cultura: possibilidades ao desenvolvimento do pensamento decolonial
}

\author{
Educación y Cultura: posibilidades para el desarrollo del pensamiento \\ decolonial \\ Education and Culture: possibilities for the development of decolonial
thinking
}

\author{
Me. Rodrigo Garcez ${ }^{1}$
}

\begin{abstract}
Resumo
O texto é fruto de uma pesquisa bibliográfica exploratória que visa a analisar a problemática da educação intercultural como meio de emancipação e desenvolvimento humano. No percurso investigativo proposto, a pesquisa situa-se entre os campos da Educação, Cultura e Direitos Humanos. Primeiramente é feita uma breve análise das principais categorias que atuam no processo de influência da colonização e da colonialidade na imagem subjetiva da realidade do povo colonizado, relacionando esta imagem subjetiva formada com a dinâmica do conceito de performatividade. Em seguida, aponta como este processo afeta o indivíduo na construção de suas funções psicológicas superiores no campo da linguagem através da educação e da música. Por último, são discutidos os possíveis caminhos e alternativas para a construção de uma nova rede de significados que possibilitem o desenvolvimento de um pensamento decolonial através da educação e da cultura.
\end{abstract}

Palavras-chave: Educação; Cultura; Música; Decolonialidade; Desenvolvimento humano.

\section{Resumen}

El texto es resultado de una investigación bibliográfica exploratória que tiene como objetivo analisar los problemas de la educación intercultural como un medio de capacitación y el desarrollo humano. En el transcurso de la investigación propuesta, la misma se basa entre los campos de la educación, cultura y derechos humanos. Primeramente se hizo una breve analise de las principales categorias que actuan en el proceso de influencia de la colonización y del colonialismo en la imagen subjetiva de la realidad del pueblo colonizado. Relacionando ésta imagen subjetiva formada con la dinamica del concepto de performatividad. En seguida, apunta como éste proceso afecta el individuo en la construcción de sus funciones psicológicas superiores en el campo de lenguaje a través de la educación y de la música. Por último, son discutidos los posibles caminos de una nueva red de significados que posibiliten el desenvolvimiento de un pensamiento decolonial a través de la educación y de la cultura.

Palabras-clave: Educación; Cultura; Música; Colonialidad; Desarrollo Humano.

\section{Abstract}

The text is the result of an exploratory biliographic research that analyze the problem of intercultural education as a means of emancipation and human development. In the proposed research course, the research is located between the fields of Education, Culture and Human Rights. First, a brief analysis is made of the main categories that act in the process of influence of colonization and coloniality on the subjective image of the reality of the colonized people, relating this subjective image formed with the dynamics of the concept of performativity. He then points out how this process affects the individual in the construction of his higher psychological functions in the field of language through education and music. Finally, the possible ways and

1 Mestre em Educação; Universidade Federal da Fronteira Sul UFFS; Chapecó, Santa Catarina, Brasil; rodrigogarcez@ hotmail.com. Trabalho apresentado no I Seminário Latino-Americano de Estudos em Cultura SEMLACult, Foz do Iguaçu/PR, Brasil, 2017. 
alternatives for the construction of a new network of meanings that allow the development of a decolonial thought through education and culture are discussed.

Keywords: Education; Culture; Music; Decoloniality; Human development.

\section{Introdução}

O desenvolvimento do ser humano ocorre de maneira multidimensional. Esta multidimensionalidade é identificada na riqueza das manifestações de suas criações, sejam elas objetivas ou não. De uma forma geral, segundo Kant (1985), o ser humano tende naturalmente a desenvolver-se e sair do estado de selvageria, desde que não haja uma forma poder que o mantenha como tal. Porém, esta intenção é identificada nos processos de colonização, e mesmo que o processo colonizatório já tenha cessado sua influência direta, esse continua a exercer força na mentalidade e na cultura dos povos submetidos a subalternidade. Essa força pode ser percebida através das relações entre as categorias: cultura, educação e colonialidade, e pode ser superada pela dinâmica do pensamento decolonial.

\section{Cultura e culturas}

A definição de cultura evoca um pensamento multidisciplinar; logo, é percebida por enfoques distintos. E lhe são, dessa forma, atribuídos usos e finalidades distintos. Neste trabalho optou-se por utilizar o termo cultura em três concepções fundamentais sintetizados por Canedo (2009, p. 4), a saber: “[...] 1) modos de vida que caracterizam uma coletividade; 2) obras e práticas da arte, da atividade intelectual e do entretenimento; e 3) fator de desenvolvimento humano".

$\mathrm{Na}$ concepção de cultura como sendo os modos de vida que caracterizam uma coletividade, a autora se baseou na perspectiva de Botelho (2001), em que afirma que os valores, identidades e diferenças que se estabelecem na rotina do indivíduo têm sua origem na interação social entre eles. Já Chauí (1995, p. 81) complementa e alarga este conceito afirmando "que todos indivíduos e grupos são seres e sujeitos culturais".

A segunda concepção de cultura refere-se a obras e práticas de arte, atividade intelectual e de entretenimento com objetivo sobretudo econômico, e, segundo Botelho (2001), é uma produção elaborada com objetivo de alcançar públicos específicos.

A terceira concepção, segundo Canedo (2009), assume um papel como fator de desenvolvimento social, embora possa ser criticada pelo seu fim utilitarista, ela não deixa de exercer um papel na formação política e social. 
Partindo dessas percepções, entende-se que a cultura é ponto de passagem para todo desenvolvimento nos processos simbólicos individuais e sociais. E que, em uma intervenção com vistas à superação dos processos simbólicos e culturais de um povo colonizado, necessita basicamente de uma análise histórica dos efeitos que a dinâmica colonizadora exerceu sobre a própria sociedade e nos modos de pensar do colonizado e do próprio colonizador.

\section{Colonização e Colonialidade}

Segundo Quijano (2007), o conceito de colonialidade, embora vinculado ao de colonialismo, difere-se deste. O colonialismo refere-se estritamente a uma estrutura de dominação e exploração, em que o controle da política, dos recursos de produção e do trabalho provêm de outra nação e não implica, necessariamente, em relações racistas de poder. Por outro lado, a colonialidade derivada do colonialismo é mais recente, e tem se mostrado mais profunda e duradoura que o colonialismo, interferindo na intersubjetividade do mundo. E é deste "colonialismo interno" que, segundo Casanova (1965 apud QUIJANO, 2007), emerge o poder racista etnicista que opera em um Estado-nação. Neste caso em particular a perspectiva eurocêntrica de poder, no caso da estruturação de dominação que se submeteram a América Latina, a África e a Ásia a partir da conquista.

Nesta direção, Oliveira (2010), ao referenciar Quijano (2007), explicita que a inferência nesta intersubjetividade do outro refere-se à ocidentalização do imaginário do outro.

Mais especificamente, diz respeito a um discurso que se insere no mundo do colonizado, porém também se reproduz no lócus do colonizador. Nesse sentido, o colonizador destrói o imaginário do outro, invisibilizando-o e subalternizando-o, enquanto reafirma o próprio imaginário. Assim, a colonialidade do poder reprime os modos de produção de conhecimento, os saberes, o mundo simbólico, as imagens do colonizado e impõe novos. Opera-se, então, a naturalização do imaginário do invasor europeu, a subalternização epistêmica do outro não-europeu e a própria negação e o esquecimento de processos históricos não-europeus. Essa operação se realizou de várias formas, como a sedução pela cultura colonialista, o fetichismo cultural que o europeu cria em torno de sua cultura, estimulando forte aspiração à cultura europeia por parte dos sujeitos subalternizados. Portanto, o eurocentrismo não é a perspectiva cognitiva somente dos europeus, mas torna-se também do conjunto daqueles educados sob sua hegemonia. (OLIVEIRA, 2010, p. 19).

Assim, segundo Quijano (2007), a colonialidade é uma das bases do poder capitalista e se estabelece junto à classificação étnica racial como fundante neste padrão de dominação. Ainda segundo Oliveira (2010), outra característica desta dinâmica que se deve levar em consideração é a de que, por se tratar de uma estrutura de dominação subjetiva, esvazia os 
valores da sociedade colonizada e lhe atribui uma essência maléfica, polarizando-a em relação ao colonizador. Para tanto, fundamenta sua afirmação:

O mundo colonial é um mundo maniqueísta. Não basta ao colonizador limitar fisicamente o colonizado, com suas polícias e seus exércitos, o espaço do colonizado. Assim, para ilustrar o caráter totalitário da exploração colonial, o colonizador faz do colonizado uma quinta-essência do mal. A sociedade colonizada não somente se define como uma sociedade sem valores [...] O indígena é declarado impermeável à ética, aos valores. É, e nos atrevemos a dizer, o inimigo dos valores. Neste sentido, ele é um mal absoluto. Elemento corrosivo de tudo o que o cerca, elemento deformador, capaz de desfigurar tudo que se refere à estética ou à moral, depositário de forças maléficas. (FANON, 2003, p. 35-36).

Segundo Walsh (2005, p. 21), “[...] a colonialidade do ser é pensada, portanto, como a negação de um estatuto humano [...] que [...] implanta problemas reais em torno da liberdade, do ser e da história do indivíduo subalternizado por uma violência epistêmica". Fanon (1983), tratando desta negação contribui mostrando que “... o colonialismo obriga as pessoas que ele domina a perguntar-se: em realidade que sou eu?" (FANON apud WALSH, 2005, p. 22).

De uma forma sintética, de acordo com Quijano (2007), Oliveira (2010), Walsh (2005) e Fanon (2003), entende-se que o processo de colonização e colonialidade segue uma diretriz que inicia de forma objetiva concreta, em que submete o povo colonizado ao seu poder político, à sua estrutura de trabalho e a seus valores. Pode-se afirmar que esta dinâmica de naturalização da cultura eurocêntrica repercute no imaginário do colonizado, que, de uma forma geral, passa a assumir os valores e referências do colonizador em virtude do discurso usado. Isso ocorre por sedução e fetiche aos modos de viver do colonizado. E é quando permite espaço à subalternidade. Essa violência epistêmica atua subjetivamente, fazendo o indivíduo perder a referência à sua realidade sócio-histórica, à sua forma de produzir conhecimento, a seus saberes e a seu universo simbólico. Como um preventivo de segurança nesta dinâmica perversa, a sociedade colonizada ainda assume que seus modos particulares de estruturação e valores são maléficos e devem ser evitados. Logo, o processo colonizatório e de colonialidade subtrai o ser humano de sua humanidade.

Na sociedade globalizada atual, percebe-se muito mais os efeitos da colonialidade do que necessariamente um processo de colonização. A dinâmica de sedução ao modo de vida europeu capitalista e, no contraponto, a marginalização das manifestações culturais diferentes deste modelo sinalizam a efervescência deste processo de desumanização. 
No desdobramento dos efeitos da colonialidade deparamo-nos com uma tecnologia, uma cultura e um modo de regulação que implicam em julgamento, comparação e exposição, tomados como forma de controle, de atrito e de mudança. A performatividade. Este conceito engloba resumidamente a valia ou a qualidade de um indivíduo em um campo de julgamento. Em síntese, "uma equação entre riqueza, eficiência e verdade é então estabelecida" (BALL, 2010, p. 38).

Segundo Ball (2010), este conceito de performatividade trabalha com uma ideia de valor dentro do que foi estipulado como verdade ou qualidade, o qual acaba atuando na cultura e, como consequência, atua na subjetividade do indivíduo.

Percebe-se aqui pelo menos dois movimentos, um partindo do externo em direção ao interno, subjetivo do indivíduo, neste caso coercitivo, que tenta moldá-lo esmagando, desvalorizado sua percepção individual em prol de uma globalizada, estereotipada. E, por outro lado, percebe-se um movimento interno de resistência do indivíduo em relação a esta força externa. Esta reação pode ser sentida em diferentes dimensões da atuação do indivíduo, social, política, etc. Segundo Ball (2010, p. 46), "mais uma vez fabricamos a nós mesmos. Nós produzimos versões de nós mesmos para entrevistas de emprego - e cada vez mais precisamos atuar para nossos colegas potenciais".

Cada vez mais nega-se a autenticidade de ser humano, diverso, único em prol da modelagem para fazer parte desta sociedade. Nesse sentido, quando aceitação torna-se a forma de muitos sobreviverem, será analisado o papel da cultura de massa e os processos psicológicos envolvidos na alfabetização e na musicalização como fatores que, dependendo da maneira como forem geridos, podem proporcionar uma via de ressignificação da realidade aproximando-se do que Walsh (2005) chama de "Pensamento de Fronteira, tornando visíveis outras lógicas e formas de pensar, diferentes da lógica eurocêntrica dominante e de onde pode ser possível transcender a lógica da colonialidade".

\section{Alfabetização e música}

Nessa perspectiva, serão abordados na psicologia histórico-cultural os processos envolvidos na humanização do indivíduo através da educação, mais especificamente no processo de alfabetização em relação ao de musicalização. Ambos os processos instrumentalizam o indivíduo na e para a vida social e cultural enquanto membro da espécie humana. Leva-se sempre em consideração o movimento que vai do ambiente social ao individual e do individual ao coletivo. 
A tensão na relação consigo próprio e com o outro, entre o individual e o coletivo, entre o interno e o externo, dialeticamente impulsiona o desenvolvimento no ser humano das características que o tornam ímpar enquanto espécie. E, nessa direção, o processo de alfabetização e de musicalização instrumentalizam o indivíduo. Vygotsky $(2008)^{2}$ sinaliza possíveis pontos de convergência entre os processos de alfabetização que podem também ser aplicados ao processo de musicalização. Quando o autor aborda o processo interno da formação do conceito na criança, ele identifica uma dinâmica que envolve o processo de significação mediado pela palavra e a forma como isso se dá quando a criança começa a dominar a fala externa. No domínio da fala externa, Vygotsky (2008) verificou que a criança começa por uma palavra; em seguida, passa a relacionar duas ou mais palavras entre si, progredindo de frases simples a frases mais complexas até chegar ao que ele chama de fala coerente.

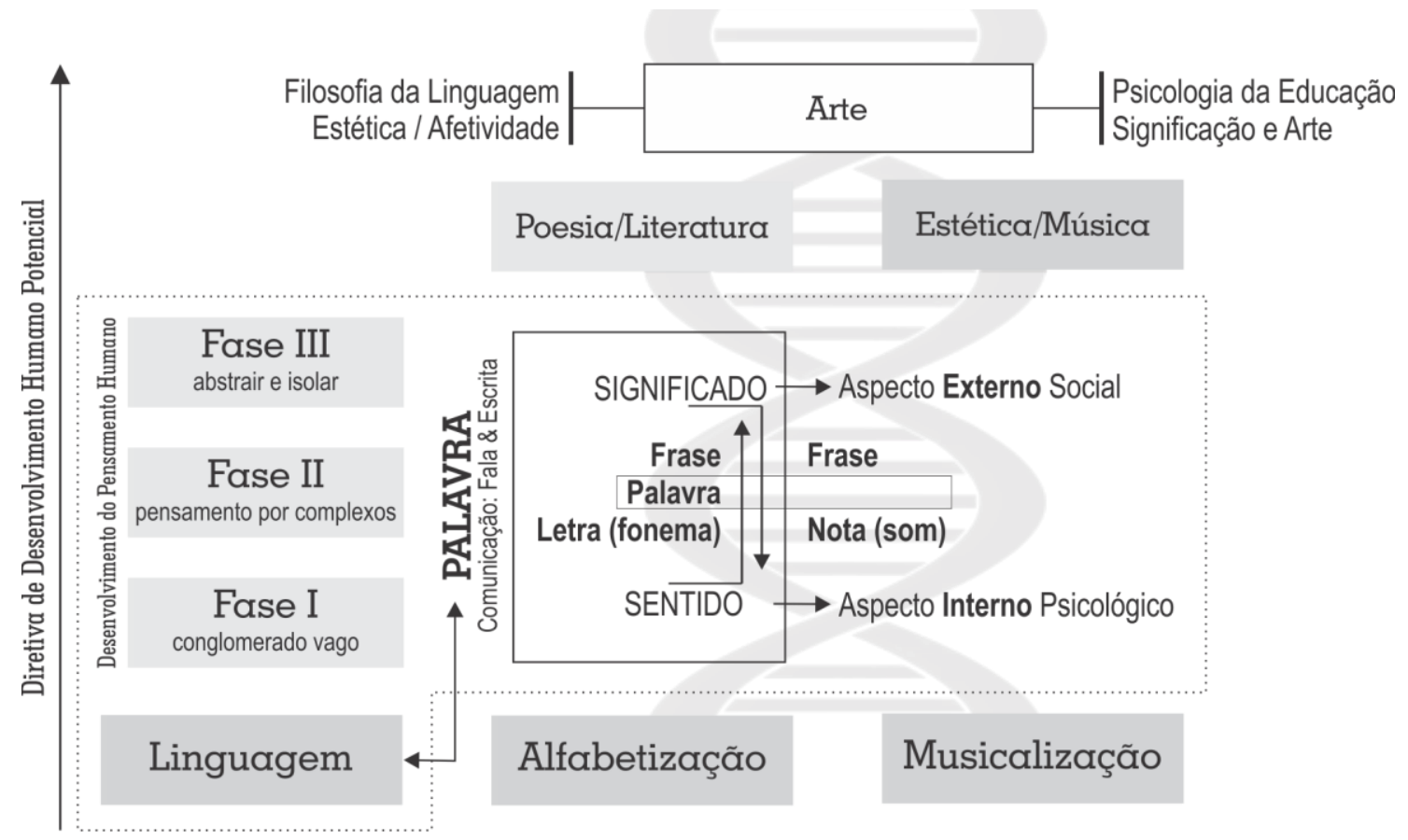

Figura 1 - Mapa mental dos processos psicológicos entre alfabetização e música Fonte: Arquivo pessoal do pesquisador.

Observa-se que o desenvolvimento do pensamento humano passa por fases bem definidas, porém não lineares, e que a palavra é o mediador desse desenvolvimento. A palavra

2 Embora em um primeiro momento a escolha deste autor para fundamentar os processos psicológicos, parece vir de encontro a estrutura de um trabalho que se direciona a privilegiar o pensamento decolonial, por outro lado, num segundo momento, servirá de conexão como referencial teórico comum para a aproximação entre a área educacional e a cultural, elencando assim categorias comuns na área educacional à uma nova perspectiva de compreensão do pensamento decolonial, fornecendo base para uma posterior reconstrução epistêmica. 
é entendida como uma unidade significativa da linguagem interna e externa do indivíduo. $\mathrm{O}$ aspecto interno tem relação com o sentido que o indivíduo atribui a ela, e o aspecto externo comunicativo associa-se ao significado construído coletivamente.

$\mathrm{Na}$ criança, o sentido e o significado têm movimentos contrários e complementares: o sentido é construído do fonema à frase, enquanto o significado da palavra inicia-se na frase, como uma unidade que proporciona a possibilidade da significação das partes, neste caso, as palavras. No processo de musicalização, o processo de aprendizagem da criança se processa de forma semelhante, indo da percepção dos sons até a apropriação de uma frase melódica e do conjunto de frases à unidade música. Porém, na dinâmica da linguagem, o processo de significação ocorre em função da palavra. Como a música não apresenta essa fase, o processo de significação deve ser analisado de forma a englobar outros elementos e, consequentemente, serem formadas outras unidades significativas de análise. Nas últimas pesquisas de Vygotsky (1999), ele buscava a compreensão dessas unidades, envolvendo a busca do sentido através das relações com a afetividade, as emoções e a arte.

Pode-se afirmar que a música e alfabetização se afinam e desafinam em relação ao ponto sob o qual são observadas. São processos que ocorrem em espiral, porque, uma vez que o indivíduo assimilou determinada compreensão acerca do processo, seja musical ou alfabético, na próxima vez que tiver contato com o mesmo conteúdo aprofundará suas relações e percepções, se existir sentido a ele. Vê-se isso na dinâmica histórica dos processos, que eram valorizados um em relação ao outro à medida que eram valorizadas ora a razão ora a emoção, uma em detrimento da outra. Por outro lado, se observadas em três dimensões, percebe-se que ambas nunca se tocam, pois são campos de conhecimento distintos ligados, neste caso, pela ponte da linguagem na perspectiva histórico-cultural. Isso possibilita um campo de pesquisa comum, uma vez que proporciona uma compreensão mais sistêmica das nuances envolvidas no processo de ensino-aprendizagem com vistas ao desenvolvimento do humano.

No momento em que a arte, a afetividade e as emoções se tornam responsáveis pelo desenvolvimento de novas funções psicológicas superiores, entende-se que o processo de significação da música pode estar ali contido. Isso porque a emoção e a afetividade, equilibradas com a racionalidade, também são os fatores preponderantes de sentido na alfabetização e na musicalização e, em última análise, na própria dinâmica de emancipação enquanto ser candidato à humanidade. 
A arte é o social em nós, e o se o seu efeito se processa em um indivíduo isolado, isto não significa, de maneira nenhuma, que suas raízes e essência sejam individuais. [...] O social existe até onde há apenas um homem e as suas emoções. [...] A refundição das emoções fora de nós realiza-se por força de um sentimento social que foi objetivado, levado para fora de nós, materializado e fixado nos objetos externos da arte, que se tornaram instrumento da sociedade. (VYGOTSKY, 1999, p. 315).

Uma vez que as funções psicológicas superiores não são estáticas e se alteram em virtude das relações sociais e internas, entende-se que a própria rede de significações pode ser alterada. Logo, tendo consciência de que as relações de poder não desaparecem, elas poderão ser reconfiguradas. Oliveira (2010), comenta acerca do "posicionamento crítico de fronteira" proposto por Walsh (2005), e aponta este como alternativa possível de superação da lógica colonial.

O pensamento de fronteira significa tornar visíveis outras lógicas e formas de pensar, diferentes da lógica eurocêntrica dominante. O pensamento de fronteira se preocupa com o pensamento dominante, mantendo-o como referência, como vimos em Fanon, mas sujeitando-o ao constante questionamento e introduzindo nele outras histórias e modos de pensar. Walsh considera essa perspectiva como componente de um projeto intercultural e decolonizador, permitindo uma nova relação entre conhecimento útil e necessário na luta pela decolonização epistêmica. Esse pensamento crítico pode se constituir desde a colonialidade e propõe que se crie novas comunidades interpretativas que ajudem a vero mundo de uma perspectiva "outra". Esse enfoque quer se constituir como um projeto alternativo ao racismo epistêmico e à colonialidade do ser, do saber e do poder. (OLIVEIRA, 2010, p. 26).

\section{Conclusões}

À guisa de conclusão, torna-se premente para o desenvolvimento integral do ser humano a superação dos processos e forma de pensar da colonialidade que atua na sociedade e no indivíduo, muito embora a liberdade que se apresenta para tal esteja sitiada. Logo, segundo as premissas elencadas, a forma com que encaramos a cultura e a arte através da educação, ou de uma pedagogia que privilegie esses aspectos de superação da colonialidade, poderá ser uma das maneiras para alcançarmos uma nova rede de sentidos e significados à nossa existência individual e social histórica. E mesmo sabendo que a dinâmica do poder não deixará de xistir, os esforços educacionais neste sentido poderão mudar sua configuração, com vistas a uma que valorize e respeite a interculturalidade, étnica, territorial e social.

\section{Referências}


.BALL, Stephen J. Performatividades e fabricações na economia educacional: rumo a uma sociedade performativa. Educação e realidade, v. 35, n. 2, p. 77-55, 2010.

BOTELHO, I. Dimensões da cultura e políticas públicas. São Paulo Perspec., São Paulo, v. 15, n. 2, p. 73-83, Apr. 2001. Disponível em:

$<$ http://www.scielo.br/scielo.php?script=sci_arttext\&pid=S0102-

$88392001000200011 \& \operatorname{lng}=$ en\&nrm=iso>. Acesso em: 21 jul. 2017.

http://dx.doi.org/10.1590/S0102-88392001000200011.

CANEDO, D. P. Cultura é o quê? Reflexões sobre o conceito de cultura e a atuação dos poderes públicos. In: V ENECULT - Encontro de Estudos Multidisciplinares em Cultura, Faculdade de Comunicação/UFBA, Anais... Salvador, Bahia, 27 a 29 de maio de 2009.

CHAUÍ, M. Cultura política e política cultural. Estudos Avançados, São Paulo, v. 9, n. 23, p. 71-84, 1995.

FANON, F. Los condenados de la tierra. México: Fondo de Cultura Económica, 2003.

CASTRO-GÓMEZ, S.; GROSFOGUEL, R. (orgs.). El giro decolonial. Reflexiones para una diversidad epistémica más allá del capitalismo global. Bogotá: Universidad JaverianaInstituto Pensar, Universidad Central-IESCO, Siglo del Hombre Editores, 2007.

KANT, I. Resposta à pergunta: o que é esclarecimento. In: Textos seletos. Petrópolis: Vozes, 1985.

OLIVEIRA, L. F. de; CANDAU, V. M. F. Pedagogia decolonial e educação antirracista e intercultural no Brasil. Educ. rev., Belo Horizonte, v. 26, n. 1, p. 15-40, Apr. 2010.

Disponível em: <http://www.scielo.br/scielo.php? script=sci_arttext\&pid=S0102-

$46982010000100002 \& \operatorname{lng}=e n \& n r m=i s o>$. Acesso em: 2 maio 2017.

http://dx.doi.org/10.1590/S0102-46982010000100002.

QUIJANO, A. Colonialidad del poder y clasificación social. In: CASTRO-GÓMEZ, S.;

GROSFOGUEL, R. (orgs.). El giro decolonial. Reflexiones para una diversidad epistémica más allá del capitalismo global. Bogotá: Universidad Javeriana-Instituto Pensar, Universidad Central-IESCO, Siglo del Hombre Editores, 2007. p. 93-126.

VYGOTSKY, L. S. Psicologia da arte. São Paulo: Martins Fontes, 1999.

Pensamento e linguagem. 4. ed. São Paulo: Martins Fontes, 2008.

WALSH, C. Pensamiento crítico y matriz (de)colonial. Reflexiones latinoamericanas.

Quito: Ediciones Abya-yala, 2005. 